\title{
Schizaeales da Chapada Diamantina, Bahia, Brasil
}

\author{
Schizaeales from Chapada Diamantina, Bahia, Brazil
}

\author{
Jamile Lima Ferreira ${ }^{1}$, Efigênia de Melo ${ }^{1}$ \& Fabiana Regina Nonato ${ }^{2,3}$
}

\begin{abstract}
Resumo
A Chapada Diamantina é a porção da Cadeia do Espinhaço localizada na posição central do Estado da Bahia. Está inserida no bioma Caatinga e compreende 58 municípios. O presente trabalho registra o levantamento florístico, as descrições e as ilustrações de 11 espécies de Schizaeales encontradas na Chapada Diamantina, além de chaves de identificação para famílias e espécies. As espécies encontradas foram: Anemia dentata Gardner ex Field \& Gardner, A. ferruginea Humb. \& Bonpl. ex Kunth, A. hirsuta (L.) Sw., A. oblongifolia (Cav.) Sw., A. phyllitidis (L.) Sw., A. rutifolia Mart., A. tomentosa (Savigny) Sw. e A. villosa Humb. \& Bonpl. ex Willd., Lygodium venustum Sw., L. volubile Sw., Schizaea elegans (Vahl) Sw.

Palavras-chave: Anemia, florística, Lygodium, Schizaea.
\end{abstract}

\begin{abstract}
The Chapada Diamantina is part of the Cadeia do Espinhaço located in the center of Bahia state. It lies within the Caatinga biome and comprises 58 municipalities. This paper reports on a floristic survey, descriptions and illustrations of 11 species of Schizaeales from the Chapada Diamantina, providing identification keys for families and species. These species were: Anemia dentata Gardner ex Field \& Gardner, A. ferruginea Humb. \& Bonpl. ex Kunth, A. hirsuta (L.) Sw., A. oblongifolia (Cav.) Sw., A. phyllitidis (L.) Sw., A. rutifolia Mart., A. tomentosa (Savigny) Sw. and A. villosa Humb. \& Bonpl. ex Willd., Lygodium venustum Sw., L. volubile Sw., Schizaea elegans (Vahl) Sw.
\end{abstract}

Key words: Anemia, floristic, Lygodium, Schizaea.

\section{Introdução}

Schizaeales C. F. Reed constitui uma ordem de samambaias morfologicamente diversa, com representantes de hábito herbáceo (Schizaeaceae e Anemiaceae) e escandente (Lygodiaceae) e frondes estéreis e férteis com lâminas diferenciadas, ausência de soros bem definidos e esporângios com ânulo apical ou subapical. É formada por três famílias: Schizaeaceae, com os gêneros Actinostachys Wall. e Schizaea Sm., Lygodiaceae, com o gênero Lygodium Sw., e Anemiaceae, com o gênero Anemia Sw., incluindo Mohria Sw. (Smith et al. 2006).

Seus representantes são encontrados em áreas de caatinga, cerrados, matas e afloramentos rochosos; em rocha exposta, margens de rios ou como epífitas (Tryon \& Tryon 1982; Smith et al. 2006). São distribuídos na América Tropical, África e sul da Índia, com aproximadamente 170 espécies em quatro gêneros (Smith et al. 2006), destas 78 ocorrem no Brasil (Barros et al. 2010a,b,c).

Segundo Tryon (1972), o Sudeste e Sul do Brasil, junto ao México e os Andes representam centros primários de distribuição de espécies de samambaias, devido ao grande número de espécies e alto grau de endemismo registrado em comparação com áreas correspondentes. Complementarmente, Mickel (1982) afirma que a maior concentração das espécies de Anemia está na região Sudeste do Brasil.

O presente trabalho objetiva o levantamento florístico dos representantes da ordem Schizaeales

\footnotetext{
${ }^{1}$ Universidade Estadual de Feira de Santana, Av. Transnordestina s/n, Bairro Novo Horizonte, 44036-900, Feira de Santana, BA.

${ }^{2}$ Centro de Pesquisas Gonçalo Moniz, Fundação Oswaldo Cruz, R. Waldemar Falcão 121, Candeal, 40296-710, Salvador, BA.

${ }^{3}$ Autor para correspondência: frnonato@bahia.fiocruz.br
} 
para a Chapada Diamantina, Bahia, a fim de enriquecer os conhecimentos sobre a flora baiana e auxiliar na taxonomia das espécies do grupo, apresentando chaves de identificação para famílias e espécies, descrições, ilustrações, comentários, observações de campo e distribuição geográfica das espécies encontradas.

\section{Material e Métodos}

A Chapada Diamantina ocupa uma posição central no Estado da Bahia e compreende 58 municípios (Bandeira 1995). É a parte setentrional da Cadeia do Espinhaço e está inserida no bioma da Caatinga.

A área é caracterizada por um mosaico de vegetação composto por matas de galeria, cerrado, campo rupestre e caatinga. O relevo é bastante acidentado, de 200 a $800 \mathrm{~m}$, com elevações isoladas de até $2.033 \mathrm{~m}$, como encontrado no Pico do Barbado na região do Município de Abaíra (Franca-Rocha et al. 2005).

Foram realizadas expedições de coleta entre 2007 e 2008 a 34 municípios. O material coletado foi herborizado seguindo as técnicas de Windisch (1992) e se encontra depositado no herbário HUEFS. Foram examinadas as coleções depositadas nos herbários ALCB, CEPEC, HB, HRB, HUEFS, IPA, MBM, PEUFR, RB, SP, SPF, UFP e UPCB. Também foram analisados materiais disponíveis em bancos de dados virtuais, principalmente fotografias de materiais-tipo dos herbários B, MO e NY, listados conforme Thiers (2010).

Os dados sobre distribuição foram retirados de literaturas especializadas, de coleções dos herbários visitados e de bancos de dados virtuais supracitados.
O sistema de classificação utilizado, a descrição morfológica da ordem Schizaeales e a circunscrição de famílias seguem Smith et al. (2006). A circunscrição de gêneros seguem Tryon \& Tryon (1982), Kramer (1990) (Anemia, Lygodium e Mohria) e Moran(1995) (Actinostachys e Schizaea), e as espécies foram descritas a partir da análise do material da área de estudo. Os termos técnicos seguem Lellinger (2002). Neste trabalho, é utilizado o termo "segmento fértil" preferencialmente a "esporangióforos", "soróforo", ou "monângio" para descrever a parte reprodutiva dos espécimes, devido a estes termos não corresponderem conceitualmente àquelas descritas e ilustradas no presente trabalho. A abreviatura dos autores dos táxons segue PichiSermolli (1996).

\section{Resultados e Discussão}

\section{Schizaeales}

Plantas terrestres ou rupícolas, raramente epífitas. Rizoma reptante a ereto, tricomas simples e achatados, com várias camadas de células (ciliformes), escamas raro presentes. Frondes com crescimento determinado ou não, hemidimorfas, raramente monomorfas, eretas a prostradas, geminadas ou não. Estípite não articulado, sulcado ou não, amarelo a enegrecido. Lâmina simples ou dividida dicotomicamente, ou uma a mais vezes pinada. Nervuras livres, uma ou mais bifurcadas, raro anastomosadas. Esporângios geralmente em pinas ou lobos fortemente modificados, sésseis a curto-pedunculados, obovóides ou piriformes, ânulo apical ou subapical, estômio definido, abrindo por uma fenda vertical, pseudo-indusiado ou não. Esporos monoletes ou triletes, ânulo subapical a apical (Reed 1947; Smith et al. 2006).

A Ordem inclui três famílias, que podem ser diferenciadas com base na chave a seguir.

\section{Chave de identificação para as famílias da ordem Schizaeales}

1. Plantas escandentes; frondes de crescimento indeterminado; indumento de tricomas amarronzados a enegrecidos; pseudo-indúsio cartáceo; esporos triletes 2. Lygodiaceae

1'. Plantas não escandentes; frondes de crescimento determinado; indumento de tricomas hialinos a marrons; pseudo-indúsio ausente; esporos triletes ou monoletes.

2. Lâmina simples a dicotomicamente dividida; linear a flabelada; segmentos férteis apicais, digitados ou pinatítifidos; esporos monoletes 3. Schizaeaceae

2'. Lâmina pinada a tripinado-pinatífida; oblonga, lanceolada ou triangular; segmentos férteis em par basal de pinas modificadas; esporos triletes 1. Anemiaceae 
Anemiaceae Link, Handb. Erken. Gew. 3: 8. 1833.

Anemiaceae é representada unicamente pelo gênero Anemia, com cerca 120 espécies registradas para a América Tropical, dez na África e uma no sul da Índia (Mickel 1982; Mickel \& Smith 2004).
No Brasil, são encontradas 69 espécies (Barros et al. 2010a). Para a Chapada Diamantina são registradas oito espécies.

Anemia Sw., Syn. Fil. (Swartz) 6: 155. 1806.

\section{Chave de identificação para as espécies de Anemia}

1. Estípite achatado.

2. Lâmina com nervuras anastomosadas

1.5. A. phyllitidis

2'. Lâmina com nervuras livres bifurcadas.

3. Lâmina pinado-pinatífida a pinado-pinatisecta

1.8. A. villosa

3'. Lâmina pinada.

4. Lâmina elíptica, lanceolada ou espatulada; pinas laterais oblanceoladas e margem crenado-denteada; uma única pina basal modificada 1.1. A. dentata

4'. Lâmina oblonga; pinas laterais oblongas e margem inteira; par basal de pinas modificado 1.4. A. oblongifolia

1'. Estípite cilíndrico ou anguloso.

5. Estípite cilíndrico.

6. Lâmina com textura membranácea, pinas laterais sésseis. Pinas férteis ocorrendo até $0,2 \mathrm{~cm}$ de distância do par basal de pinas estéreis 1.3. A. hirsuta

6'. Lâmina com textura cartácea a subcoriácea, pinas laterais pecioladas. Pinas férteis ocorrendo mais de $1 \mathrm{~cm}$ do par basal de pinas estéreis 1.6. A. rutifolia

5'. Estípite anguloso.

6. Estípite atropurpúreo. Lâmina com margem inteira a crenado-serreada, textura coriácea .... 1.2. A. ferruginea

6'. Estípite amarelado a castanho. Lâmina com margem denteada, textura cartácea a subcoriácea 1.7. A. tomentosa

1.1. Anemia dentata Gardner ex Field \& Gardner, Sert. Pl. ad. t. 70. 1844. 1844. Fig. 1a-c

Plantas terrestres ou rupícolas. Rizoma 4-7 mm diâm., subereto a ereto, castanhos, tricomas ca. $1 \mathrm{~mm}$, ferrugíneos. Frondes hemidimorfas, prostradas a eretas. Fronde com estípite 0,1-7,1 $\times 0,05-0,14 \mathrm{~cm}$, achatado, sulcado, esverdeado a castanho, tricomas ca. $1 \mathrm{~mm}$ compr., ferrugíneos, concentrados na base do estípite; lâmina $0,7-5,1$ $\times(1)-1,4-3,2 \mathrm{~cm}$, pinada, elíptica, lanceolada ou espatulada, base truncada a cuneada, ápice cordado ou lobado, às vezes bilobado; pina apical subconforme; pinas laterais $(0,5)-0,8-1,5 \times$ 0,16-0,7 cm, 7-14 pares, alternas, oblanceoladas, base acuminada ou cordada, ápice redondo, margem crenada a crenado-denteada, cartácea, nervuras livres 2-5 bifurcadas, sésseis; raque 0,3-1 mm larg., achatada, sulcada, glabrescente a pubescente. Segmentos férteis $0,9-5,4 \times 0,3-0,7$ $\mathrm{cm}$, subglabros, tricomas ca. $1 \mathrm{~mm}$, peciólulo dos segmentos 3,9-20 × 0,03-0,1 cm, pubescente. Única pina fértil ereta inserida $3-10 \mathrm{~mm}$ do par basal de pinas estéreis; maior 3 vezes ou mais que lâmina.

Material examinado: Contendas do Sincorá, 27.IV.2003, L.A. Junior et al. 02 (ALCB). Morro do Chapéu, 27.VI.1996, R.M. Harley et al. PCD 3122 (ALCB, CEPEC, HRB, HUEFS, SPF). Rio de Contas, 2.I.2000, A.M. Giulietti \& R.M. Harley et al. PCD 1672 (HUEFS).

A grande maioria dos espécimes apresenta somente uma das pinas do par basal modificada em segmento fértil, enquanto que a outra permanece semelhante às demais da fronde. $\mathrm{A}$ existência do par basal de pinas modificadas só ocorreu em alguns exemplares coletados no município de Rio de Contas. Nestes casos, em alguns espécimes, uma das pinas se desenvolve muito menos que a outra pina (às vezes não apresentando esporângios) em outros, as duas se desenvolvem com igual tamanho. Os espécimes 


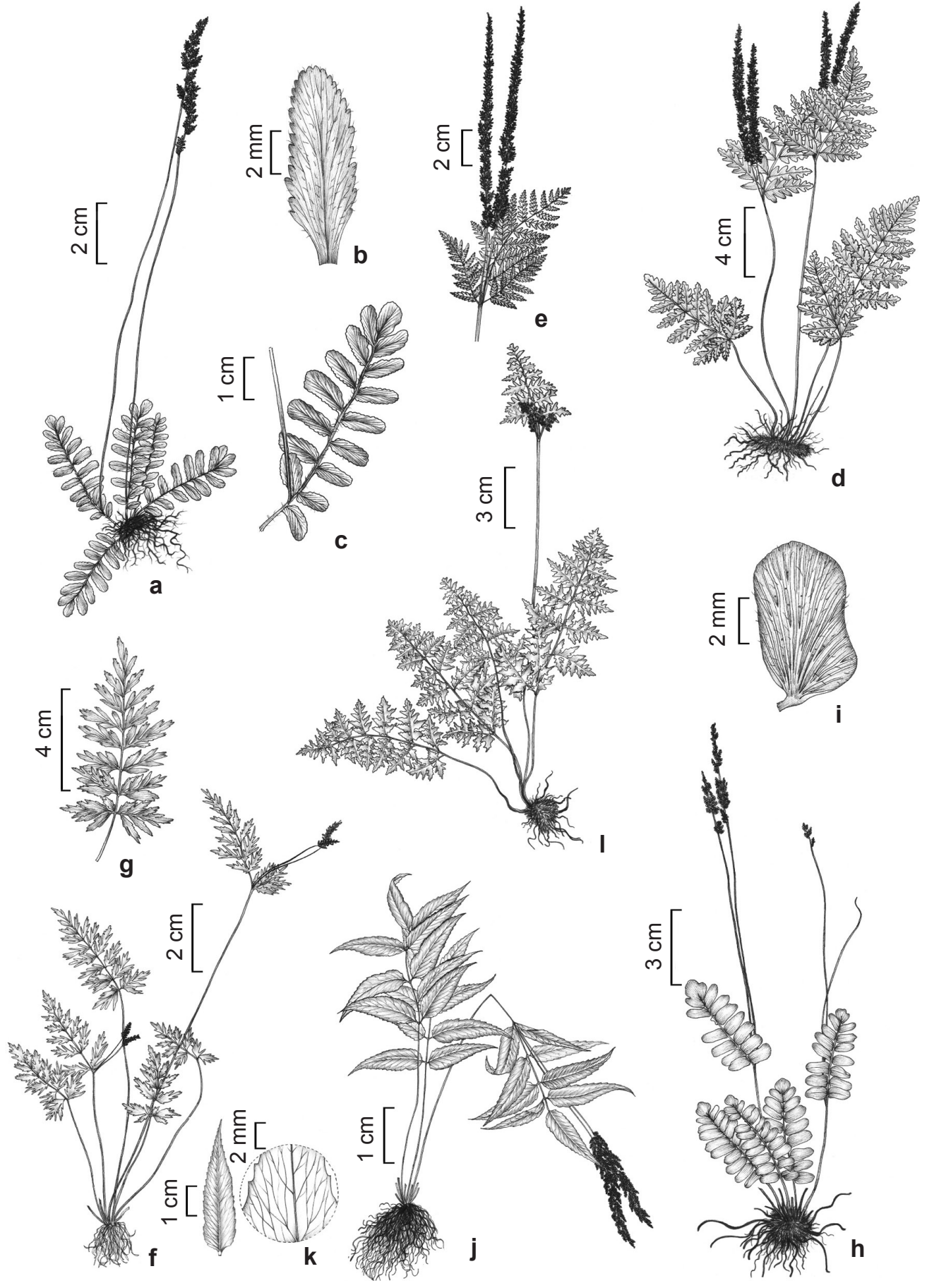

Figura 1 -a-c. Anemia dentata Gardner ex Field \& Gardner (Giulietti 1672) - a. hábito; b. pina estéril; c. fronde fértil. d-e. Anemia ferruginea Humb. \& Bonpl. ex Kunth (Hage 297, Stannard H51586) - d. hábito; e. fronde fértil. f-g. Anemia hirsuta (L.) Sw. (Giulietti 1673) - f. hábito; g. lâmina. h-i. Anemia oblongifolia (Cav.) Sw. (Harley H52093) - h. hábito; i. pina estéril. j-k. Anemia phyllitidis (L.) Sw. (Orlandi 207) - j. hábito; k. nervuras anastomosadas. 1. Anemia rutifolia Mart. (Matos 1057) - 1. hábito.

Figure 1 - a-c. Anemia dentata Gardner ex Field \& Gardner (Giulietti 1672) - a. habit; b. sterile pinna; c. fertile frond. d-e. Anemia ferruginea Humb. \& Bonpl. ex Kunth (Hage 297, Stannard H51586) - d. habit; e. fertile frond; f-g. Anemia hirsuta (L.) Sw. (Giulietti 1673) - f. habit; g. leaf blade. h-i. Anemia oblongifolia (Cav.) Sw. (Harley H52093) - h. habit; i. sterile pinna. j-k. Anemia phyllitidis (L.) Sw. (Orlandi 207) - j. habit; k. anastomosing veins. 1. Anemia rutifolia Mart. (Matos 1057) - 1. habit. 
maiores possuem estípite mais longo e mais delgado que os exemplares menores, embora todos férteis. Podem também apresentar variações no indumento da raque, na qual as frondes estéreis podem ser mais pubescentes que as frondes férteis.

Foi observada em campo a ocorrência frequente de Anemia dentata sobre afloramentos rochosos, sendo bastante resistente ao sol, se desenvolvendo junto a Selaginella convoluta (Arn.) Spring (Selaginellaceae).

Espécie endêmica do Brasil, ocorrendo nos estados de Alagoas, Bahia, Minas Gerais, Pernambuco e Piauí. Na Chapada Diamantina, é bem distribuída, encontrada em beiras de estradas ou de riachos, sobre substratos rochosos e/ou arenosos e expostos ao sol.

1.2. Anemia ferruginea Humb. \& Bonpl. ex Kunth, Nov. Gen. Sp. 1: 32-33. 1815[1816]. Fig. 1d-e Plantas terrestres. Rizoma 3-7 mm diâm., curto-reptante a subereto, castanhos, tricomas ca. $6 \mathrm{~mm}$ compr., ferrugíneos. Frondes hemidimorfas, eretas. Fronde com estípite 8,6-35,2 × 0,07-0,2 $\mathrm{cm}$, anguloso, sulcado a bisulcado, atropurpúreo a enegrecido na base, tricomas ca. $6 \mathrm{~mm}$ compr., concentrados na base e mais espaçados na porção distal; lâmina $(4,7)-8,2-12,9 \times(3,4)-4,5-6,3$ $\mathrm{cm}$, bipinada a bipinado-pinatífida, deltóide, base truncada, ápice obtuso; pina apical não conforme; pinas laterais $0,2-5,5 \times 0,1-2,3 \mathrm{~cm}$, 10-16 pares, alternas a raramente opostas na base, triangulares, base truncada, ápice agudo, margem inteira a crenado-serreada, coriácea; raque $0,5-1$ mm larg., achatada, sulcada, hirsuta; peciólulo inconspícuo a 0,6-3 × 0,5-0,6 mm; pínulas estéreis $0,2-1,8 \times 0,1-0,7 \mathrm{~cm}$, sésseis, nervuras livres $3-5$ bifurcadas; peciólulo secundário inconspícuo a 1 $\times 0,5 \mathrm{~mm}$. Segmentos férteis 8,4-21,6 × 0,4-1,4 $\mathrm{cm}$, pubescente, tricomas amarelados; peciólulo dos segmentos $2,2-5,4 \times 0,04-1,3 \mathrm{~cm}$. Par de pinas férteis eretas inseridas $0,3-1,2 \mathrm{~cm}$ de distância do par basal de pinas estéreis; cerca de 2 a 3 vezes maior que a lâmina.

Material examinado: Abaíra, 25.II.1992, B. Stannard et al. H51586 (CEPEC, HUEFS, SP, SPF). Rio de Contas, 23.VII.1979, J.L. Hage et al. 297 (CEPEC).

Em Anemia ferruginea a lâmina foliar apresenta margem que varia de inteira a crenadoserreada, caracterizando indivíduos com morfologia variável. É uma espécie semelhante a $A$. tomentosa (Savigny) Sw., pois possuem fronde com mesmo padrão de divisão. Nos materiais analisados, ambas as espécies possuem ora segmentos agudos, ora segmentos mais arredondados. Estas características também são utilizadas para segregar as respectivas variedades dentro destas espécies. Devido à existência de vários espécimes com caracteres intermediários, optou-se por utilizar aqueles caracteres mais marcantes para segregá-los em $A$. ferruginea e $A$. tomentosa.

A espécie é distribuída desde a América Central até norte da América do Sul e Brasil (Amazonas, Bahia, Distrito Federal, Espírito Santo, Goiás, Maranhão, Mato Grosso, Minas Gerais, Paraíba, Paraná, Pernambuco, Rio de Janeiro, Rio Grande do Sul, Santa Catarina, São Paulo, Sergipe). Na Chapada Diamantina, possui distribuição restrita ao sul. Não foi coletada nas expedições realizadas.

\subsection{Anemia hirsuta (L.) Sw., Syn. Fil. (Swartz) 156. 1806. Fig. 1f-g}

Plantas terrestres. Rizoma 5-7 mm diâm., subereto a ereto, castanhos, tricomas ca. $1 \mathrm{~mm}$, ferrugíneos. Frondes hemidimorfas, levemente prostradas a eretas. Fronde com estípite 7,2-22,5 $\times 0,02-0,08 \mathrm{~cm}$, cilíndrico, sulcado, esverdeado, tricomas ca. 1,8 mm compr., espaçados; lâmina $3,4-6,5 \times 2,3-3,4 \mathrm{~cm}$, pinado-pinatífida a pinadopinatisecta, triangular a oblonga, base truncada, ápice agudo a estreito-agudo; pinas laterais $0,5-2,9 \times 0,1-1,2 \mathrm{~cm}, 6-11$ pares, alternas a quase opostas, lanceoladas, base cuneada a obtusa, ápice agudo, margem crenada, membranácea, nervuras livres 4-5 bifurcadas, sésseis; raque 0,1-0,5 mm larg., cilíndrica, sulcada, tecido foliar ainda presente, subglabra, tricomas inconspícuos $(<0,1 \mathrm{~mm})$, curtos e retos; pina apical não conforme. Segmentos férteis $1,2-2,7 \times 0,2-0,7$ $\mathrm{cm}$, subglabros, tricomas ca. $1 \mathrm{~mm}$; peciólulo do segmento 2,3-4,6 $\times 0,02 \mathrm{~cm}$. Par de pinas férteis eretas inseridas $0,08-0,2 \mathrm{~cm}$ de distância do par basal de pinas estéreis, menor ou igual ao comprimento da lâmina.

Material examinado: Rio de Contas, 6.III.2004, R.M. Harley et al. 55034 (HUEFS); 2.I.2000, A.M. Giulietti \& R.M. Harley 1673 (HUEFS).

Encontrada desde o México, América Central, até a Colômbia e o Brasil (Alagoas, Bahia, Ceará, Distrito Federal, Minas Gerais, Pernambuco, Santa Catarina, e São Paulo). Na Chapada Diamantina, é pouco distribuída ao sul, sendo encontrada à sombra, em áreas de caatinga. 
1.4. Anemia oblongifolia (Cav.) Sw., Syn. Fil. 156. 1806.

Fig. 1h-i

Plantas rupícolas. Rizoma 8-10 mm diâm., subereto a ereto, castanho, tricomas $0,1-0,2 \mathrm{~mm}$, ferrugíneos. Frondes hemidimorfas, prostradas a eretas. Fronde com estípite $0,7-2,1 \times 0,8-1 \mathrm{~cm}$, achatado, sulcado, amarelado a castanho, tricomas ca. $2 \mathrm{~mm}$, distribuídos uniformemente; lâmina 1,7$5,3 \times 1-2,2 \mathrm{~cm}$, pinada, oblonga, base truncada, ápice redondo a lobado; pina apical não conforme; pinas laterais $0,3-1,2 \times 0,2-0,6 \mathrm{~cm}, 6-12$ pares, alternas, oblongas, base auriculada, ápice redondo, margem inteira a crenada, coriáceas, nervuras livres 2-4 bifurcadas, sésseis, pubescentes, tricomas $0,2-1,5 \mathrm{~mm}$, hialinos a acastanhados; raque $0,6-1 \mathrm{~mm}$ larg., achatada, sulcada, tricomas ferrugíneos. Segmentos férteis $1,1-4,5 \times 0,2-0,5$ $\mathrm{cm}$, subglabros, tricomas ca. $1 \mathrm{~mm}$ compr.; peciólulo do segmento 5,4-10,2 ×0,3-0,7 cm. Par de pinas férteis inseridas imediatamente abaixo do par basal de pinas estéreis, 2 a 3 vezes maiores que o segmento estéril.

Material examinado: Abaíra, 14.III.1992, R.M. Harley et al. 52093 (HUEFS). Rio de Contas, 22.XII.1988, R.M. Harley et al. 27413 (CEPEC, SPF).

Em Anemia oblongifolia R.M. Harley os tricomas foliares apresentam base firme e robusta, a qual permanece presa à lâmina quando os tricomas caem, aparentando uma cicatriz. Característica não observada em outras espécies relatadas neste estudo. Distingue-se das demais espécies pelas pinas oblongas e coriáceas, e pelo longo peciólulo da pina fértil.

Distribuída desde o México, América Central, até o norte da Argentina e Brasil (Roraima, Mato Grosso, Goiás, Piauí, Pernambuco, Sergipe, Minas Gerais, Bahia, Rio de Janeiro, São Paulo, Distrito Federal). Na Chapada Diamantina, é encontrada ao sul, sobre rochas expostas ou pouco sombreadas.

1.5. Anemia phyllitidis (L.) Sw., Syn. Fil. 155. 1806.

Fig. 1j-k

Plantas terrestres. Rizoma 5-7 mm diâm., ereto, castanho, tricomas ca. $2 \mathrm{~mm}$, castanhos. Frondes hemidimorfas. Fronde com estípite 13,2$26,9 \times 0,07-0,1 \mathrm{~cm}$, achatado, sulcado, amarelado, tricomas $0,2-0,6 \mathrm{~mm}$, castanhos a ferrugíneos; lâmina 8,5-12,1 ×6,2-11 cm, pinada, lanceolada a triangular, base truncada, ápice bifurcado; pinas apicais conformes, pinas laterais $4,3-6,3 \times$ $1,1-1,8 \mathrm{~cm}, 3-5$ pares, alternas, lanceoladas, base truncada, ápice estreito-agudo, margem denteada, membranácea, nervuras anastomosadas; peciólulo $0,8-3 \times 0,8-1 \mathrm{~mm}$; raque $0,4-0,7 \mathrm{~mm}$ larg., achatada, sulcada, glabrescente. Segmentos férteis $0,6-9,3 \times 0,8-1,2 \mathrm{~cm}$, subglabros, tricomas ca. 1 mm compr.; peciólulo do segmento 12,2-12,8 $\times$ $0,06-0,08 \mathrm{~cm}$. Par de pinas férteis eretas inseridas na axila do par basal de pinas estéreis.

Material examinado: Abaíra, 2.III.1992, T. Laessoe \& P.T. Sano H50984 (SPF). Jacobina, 23.VIII.1980, R. Orlandi 207 (ALCB, HRB, RB). Piatã, 17.XI.2007, J.L. Ferreira et al. 218 (HUEFS).

Esta espécie é distinguida das demais do gênero devido à presença de pinas com nervuras anastomosadas. Entre as espécies de Anemia encontradas na Chapada Diamantina, A. phyllitidis é a que possui as pinas apicais mais semelhantes às pinas laterais.

Distribuída desde o sul do México, América Central até Argentina e Brasil (Alagoas, Amazonas, Bahia, Ceará, Distrito Federal, Espírito Santo, Goiás, Mato Grosso, Minas Gerais, Paraná, Pernambuco, Rio de Janeiro, Rio Grande do Sul, São Paulo e Santa Catarina). Na Chapada Diamantina, esta espécie pode ser encontrada na beira de barrancos arenosos, em meio a gramíneas.

1.6. Anemia rutifolia Mart., Icon. Pl. Crypt. 112, t. 5, f. 1.1834.

Fig.11

Plantas rupícolas. Rizoma 4-11 mm diâm., curto-reptante a subereto, enegrecido, tricomas ca. $0,7 \mathrm{~mm}$ amarelado-brilhantes a castanhos. Frondes hemidimorfas, eretas e alternas. Fronde com estípite $1-7,1-(21,6) \times 0,02-0,09 \mathrm{~cm}$, cilíndrico, sulcado, amarelado a castanho, base castanho escura, tricomas ca. $0,6 \mathrm{~mm}$, castanhos; lâmina 2,8-7,2 × 1,2-4,6 cm, pinado-pinatisecta a bipinado-pinatisecta, lanceolada a ovada, base truncada, ápice agudo; pina apical não conforme; pinas laterais $0,7-2,6 \times 0,5-1,5 \mathrm{~cm}, 6-11$ pares, alternas a levemente opostas, lanceoladas, base truncada, ápice agudo, margem inteira a levemente crenada, cartácea a subcoriácea, nervuras livres 1-2 bifurcadas; peciólulo inconspícuo a ca. $2-10 \times 0,4-0,6 \mathrm{~mm}$; raque $0,1-0,6 \mathrm{~mm}$ larg., cilíndrica, sulcada a bisulcada, tricomas ferrugíneos. Segmentos férteis $0,8-4,1 \times 0,3-0,8$ $\mathrm{cm}$, subglabros, tricomas ca. $0,6 \mathrm{~mm}$ compr.; peciólulo $0,1-0,8 \times 0,04-0,07 \mathrm{~cm}$. Par de pinas férteis eretas inseridas $1,1-2,8 \mathrm{~cm}$ de distância do par basal de pinas estéreis, medindo do terço a metade do tamanho da lâmina. 
Material examinado: Rio de Contas, 17.II.1977, R.M. Harley et al. 19518 (CEPEC); 26.II.2006, F.B. Matos et al. 1035 (CEPEC, RB, UPCB); 27.II.2006, F.B. Matos et al. 1057 (CEPEC, RB, MBM).

Nesta espécie, as frondes férteis são mais eretas e seus estípites são duas a três vezes maiores que nas frondes estéreis. $\mathrm{O}$ par basal de pinas em ambas as frondes está localizado mais afastado do penúltimo par de pinas (entre 1,1 e 2,8 cm). As pínulas da lâmina foliar da fronde fértil são pinatífidas, lanceoladas a oblongas e sésseis, menores e mais estreitas que as pínulas das frondes estéreis. A dissecção e a textura da lâmina e as pinas férteis com curtos peciólulos e comprimento que nunca ultrapassa a lâmina, nos exemplares examinados, tornam Anemia rutifolia bastante distinguível das outras espécies.

Espécie encontrada no Brasil, nos estados de Minas Gerais e Bahia, sendo endêmica da Cadeia do Espinhaço. Na Chapada Diamantina, possui ocorrência restrita à região sul. Esta área está bastante sujeita ao fogo, principalmente nos meses de novembro e dezembro.

1.7. Anemia tomentosa (Savigny) Sw., Syn. Fil. 157. 1806 Fig. 2a-b

Plantas terrestres ou rupícolas. Rizoma 4-7 mm diâm., curto-reptante a subereto, castanho, tricomas ca. $2 \mathrm{~mm}$, amarelado-alaranjados. Frondes hemidimorfas, prostradas a eretas, alternas. Fronde com estípite 5,6-27,7 × 0,08-0,2 $\mathrm{cm}$, anguloso, sulcado a bisulcado, amarelado a castanho; lâmina 6,3-16 × 3,4-9,6 cm, bipinada a bipinado-pinatífida, deltóide, base truncada, ápice obtuso; pina apical não conforme; pinas laterais $0,3-5,5 \times 0,1-2,4 \mathrm{~cm}, 11-17$ pares, alternas, lanceoladas a deltóides, base truncada, ápice obtuso, margem denteada, cartácea a subcoriácea; peciólulo inconspícuo a 6-10 $\times$ 0,6-0,7 mm, amarelado; pínulas 0,2-2,6 × 0,1-1 $\mathrm{cm}$, alternas, inteiras a pinatisectas, nervuras livres 1-3 bifurcadas; peciólulo secundário inconspícuo a 0,5-0,7 × 0,4 mm; raque 0,6-1 mm larg., achatada, sulcada, pubescente, amarelada. Segmentos férteis 8,4-21,8 × 0,3-1 cm, tomentosos, amarelados; peciólulo do segmento $2,7-6,5 \times 0,06-0,1 \mathrm{~cm}$. Par de pinas férteis eretas inseridas $2-7 \mathrm{~mm}$ de distância do par de pinas estéreis basais.

Material examinado: Contendas do Sincorá, 27.IV.2003, L.A. Junior et al. 03 (ALCB, SPF). Itaetê, 17.II.2001, F.R. Nonato et al. 787 (HUEFS). Livramento de Brumado, 20.III.1980, S. Mori \& F. Benton 13494 (CEPEC, RB).
Esta espécie é bastante confundida com Anemia ferruginea, entretanto diferencia-se por apresentar tricomas amarelados a alaranjados no rizoma e na base do estípite e a textura da lâmina variando de cartácea a subcoriácea.

Distribuída desde o México, América Central, até Argentina e Brasil (Bahia, Espírito Santo, Mato Grosso, Paraíba, Paraná, Pernambuco, Piauí, Rio de Janeiro, Rio Grande do Sul, Santa Catarina e São Paulo). Na Chapada Diamantina, apresenta-se mais distribuída que $A$. ferruginea, sendo encontrada em vários municípios, em substratos rochosos ou arenosos, ou entre rochas.

1.8. Anemia villosa Humb. \& Bonpl. ex Willd., Sp. Pl. 5: 92.1810.

Fig. 2c-h

Plantas terrestres ou rupícolas. Rizoma 6-17 mm diâm., subereto a ereto, castanhos, tricomas ca. $4 \mathrm{~mm}$, castanhos, alaranjados ou avermelhados. Frondes hemidimorfas, prostradas a eretas. Fronde com estípite $1,5-45,8 \times 0,05-0,18 \mathrm{~cm}$, achatado, sulcado, amarelado a atropurpúreo, tricomas ca. $4 \mathrm{~mm}$, castanhos, alaranjados ou avermelhados; lâmina 5,1-16,5 × 2,1-10,7 cm, pinado-pinatífida a pinado-pinatisecta, lanceolada a triangular, base truncada, ápice redondo a agudo; pina apical não conforme; pinas laterais $1-6,8 \times 0,5-2,5 \mathrm{~cm}$, 9-17 pares, alternas raramente as basais opostas, lanceolada, oblonga ou triangular, base obtusa a truncada, ápice redondo a obtuso, margem inteira a crenada, cartácea, nervuras livres 3-7 bifurcadas; peciólulo inconspícuo a 1-2 × 0,5-1 $\mathrm{mm}$; raque 0,4-1 mm larg., achatada, sulcada, pubescente. Segmentos férteis 3,6-17,3 × 0,3-1,8 $\mathrm{cm}$, pubescentes, tricomas ca. $4 \mathrm{~mm}$, alaranjados a avermelhados; peciólulo do segmento $1-7,3 \times$ $0,04-0,1 \mathrm{~cm}$. Par de pinas férteis eretas inseridas 3-18 $\mathrm{mm}$ de distância do par basal de pinas estéreis, medindo quase a metade até o dobro do comprimento da lâmina.

Material examinado: Palmeiras, 1.VII.1995, M.L. Guedes et al. 2110 (ALCB). Rio de Contas, 24.III.1996, M.L. Guedes et al. 12304 (ALCB). Utinga, 22.IX.2007, J.L. Ferreira et al. 90 (HUEFS).

Esta espécie pode apresentar indivíduos com frondes extremamente lanosas, com tricomas muito longos e amarelados, contrastando com os tricomas castanhos no rizoma. Este indumento é muito semelhante àquele encontrado em Anemia trichorhiza Gardner ex Hook., entretanto esta espécie é aproximadamente cinco vezes menor que $A$. villosa, além de apresentar suas pinas 


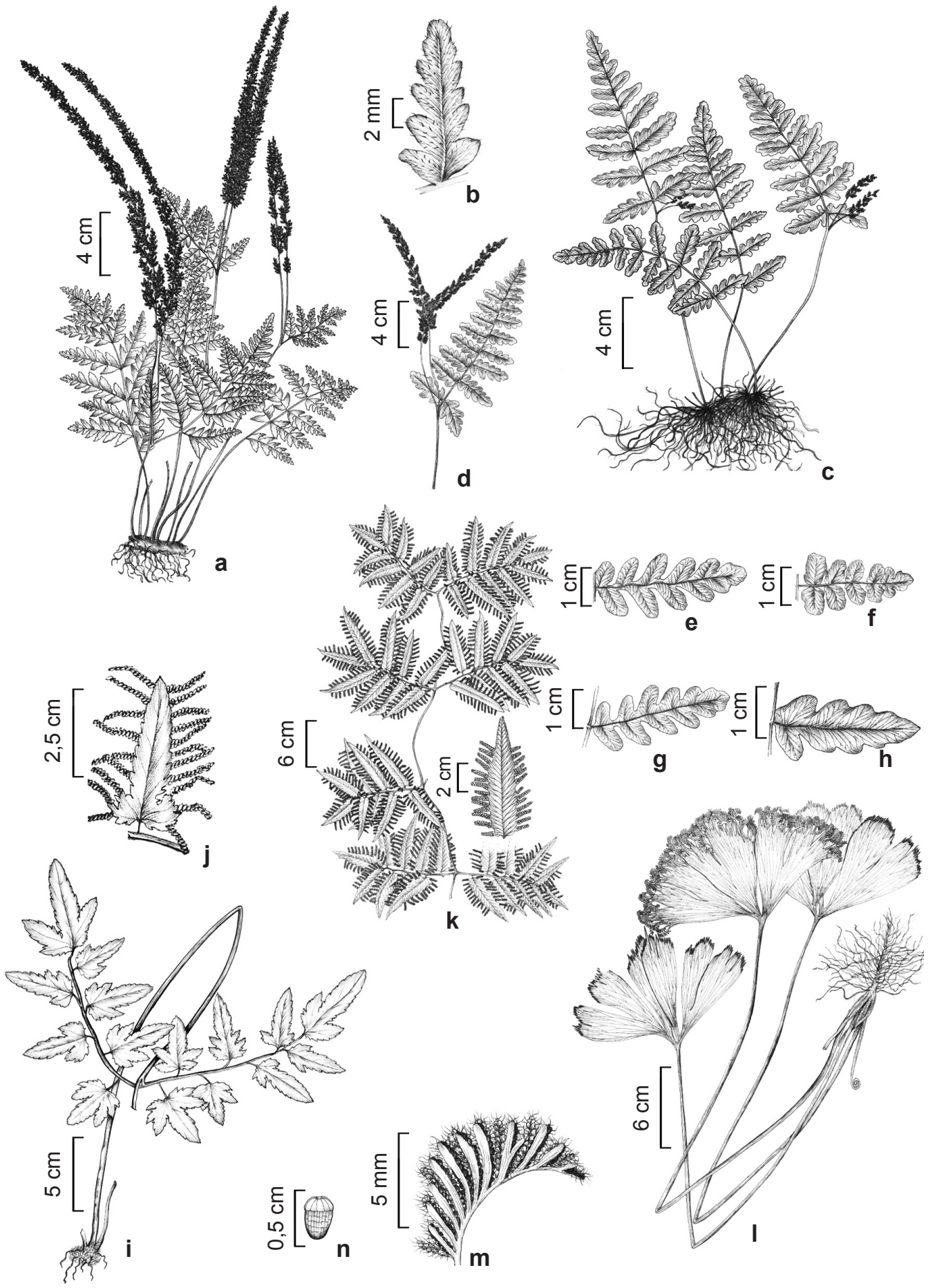

Figura 2 - a-b. Anemia tomentosa (Savigny) Sw. (Mori 13494) - a. hábito; b. pina estéril. c-h. Anemia villosa Willd. (Guedes 2110, Ferreira 90) - c. hábito; d. fronde fértil; e-h. pinas estéreis. i-j. Lygodium venustum Sw. (Melo 5294) - i. hábito; j. pina fértil. k. Lygodium volubile Sw. (Nascimento 35) - k. hábito. 1-m. Schizaea elegans (Vahl) Sw. (Ferreira 104) - 1. hábito; m. segmento fértil; n. esporângio.

Figure 2 - a-b. Anemia tomentosa (Savigny) Sw. (Mori 13494) - a. habit; b. sterile pinna. c-h. Anemia villosa Willd. (Guedes 2110 , Ferreira 90) - c. habit; d. fertile frond; e-h. sterile pinnas. i-j. Lygodium venustum Sw. (Melo 5294) - i. habit; j. fertile pinna. k. Lygodium volubile Sw. (Nascimento 35) - k. habit. 1-n. Schizaea elegans (Vahl) Sw. (Ferreira 104) - 1. habit; m. fertile segment; n. sporangium. 
férteis lanosas e prostradas, geralmente não ultrapassando a lâmina em altura.

Embora a maioria dos espécimes seja distinta com sua forma alongada e dissecção pinado-pinatífida, há variações consideráveis no tamanho e na forma que podem levar a confusão com outras espécies, como Anemia flexuosa (Savigny) Sw. Entretanto, A. flexuosa possui lâmina bipinada a bipinado-pinatífida, deltóideovada e pinas férteis freqüentemente menores que a lâmina.

Anemia villosa é a espécie mais abundante na Chapada Diamantina, facilmente encontrada em beiras de estrada, principalmente em encostas cavadas pelas águas da chuva, junto a Selaginella convoluta e em barrancos arenosos ou rochosos formados pelo garimpo, junto a Doryopteris ornithopus (Mett.) J.Sm. (Pteridaceae). Esta espécie pode apresentar fronde totalmente fértil, não somente as pinas basais, ou também podem ocorrer dois pares de pinas férteis, geralmente o último par basal ultrapassando a altura da lâmina, e o penúltimo par não ultrapassando esta altura. Também é registrada a ocorrência de indivíduos férteis formados unicamente por dois pares de pinas férteis, e a ausência de lâmina.

É distribuída no norte da América do Sul, do Peru ao Suriname e no Brasil (Bahia, Ceará, Espírito Santo, Minas Gerais, Paraná, Pernambuco, Rio de Janeiro, Santa Catarina e São Paulo). Na Chapada Diamantina, é amplamente distribuída por diversos municípios.

2. Lygodiaceae M. Roem., Handb. Allg. Bot. 3: 520. 1840.

Lygodiaceae é representada por Lygodium, com aproximadamente 25 espécies pantropicais (Smith et al. 2006). Dentre estas, cerca de oito são encontradas na América Tropical (Tryon \& Tryon 1982), sendo duas espécies registradas para o Brasil (Barros et al. 2010b).

Lygodium Sw., J. Bot. (Schrader)1800(2):7, 106. 1801.

\section{Chave de identificação para as espécies de Lygodium}

1. Lâmina bipinado-pinatífida a tripinado-pinatífida; pínulas lanceoladas a triangulares, base lobada a pinada; margem crenado-denteada 2.1. L. venustum

1'. Lâmina bipinada; pínulas lanceoladas a lineares, base truncada a biauriculada; margem denteadoserreada 2.2. L. volubile

2.1. Lygodium venustum Sw., J. Bot. (Schrader) 1801(2): 303. 1803. Fig. 2i-j

Rizoma ca. 10 mm diâm., curto-reptante, negro, tricomas ca. $0,7 \mathrm{~mm}$, enegrecidos. Estípite ca. 39,9 ×0,4 cm, cilíndrico, amarelado a castanho, tricomas basais. Frondes alternas. Lâmina bipinado-pinatífida a tripinado-pinatífida; raque $0,8-1 \mathrm{~mm}$ larg., pinas opostas; pínulas alternas; pinas estéreis 6,5-9,1 × 5,4-8,3 cm; peciólulo 6-33 × 0,4-1 mm, cilíndrico, amarelado a castanho; pínulas estéreis 2,6-8,7 × 0,9-1,9 $\mathrm{cm}$, lanceoladas a triangulares, base lobada a pinada, ápice redondo a agudo, margem crenado-denteada, cartáceas, nervuras livres 3-5 bifurcadas; peciólulo $0,8-13 \times 0,3-0,7 \mathrm{~mm}$; pinas férteis $0,5-3,3 \times 0,04-1,4 \mathrm{~cm}$; peciólulo 9-25× $0,6-1 \mathrm{~mm}$; pínulas férteis $2,2-9,1 \times 0,09-0,3 \mathrm{~mm}$, lanceoladas, base lobada a pinada, ápice estreitoagudo; peciólulo $1-9 \times 0,3-0,6 \mathrm{~mm}$. Segmentos férteis $1-11 \times 0,8-1 \mathrm{~mm}$, marginais, situados da base ao ápice das pínulas.

Material examinado: Andaraí, 2.II.2007, E. Melo et al. 5294 (HUEFS). Jacobina, 1978, I.B. Pontual 8221 (PEUFR).

Lygodium venustum pode ser facilmente reconhecida pela presença de pínulas com base lobada a pinada e margens crenado-denteadas. Os segmentos férteis de $L$. venustum são encontrados em todo o comprimento da pínula fértil, além de possuírem muitos tricomas. Em L. volubile Sw., os segmentos férteis são encontrados a partir da base até a metade do comprimento da pínula, geralmente não ocorrendo no ápice. Além disso, esses segmentos possuem menor quantidade de tricomas. Pode ser encontrada em locais mais secos, junto a L. volubile.

Esta espécie é distribuída na América Tropical, desde o México até Paraguai e Brasil (Acre, Alagoas, Bahia, Ceará, Maranhão, Mato 
Grosso, Minas Gerais, Pará, Paraíba, Paraná, Pernambuco, Rio de Janeiro, Rio Grande do Sul, Santa Catarina e São Paulo). Na Chapada Diamantina, é pouco distribuída, tendo registro somente para dois municípios.

2.2. Lygodium volubile Sw., J. Bot. (Schrader) 1801(2): 304. 1803.

Fig. 2k

Rizoma 3-4 mm diâm., longo-reptante, negro, tricomas ca. 0,6 $\mathrm{mm}$, enegrecidos, espaçados. Estípite ca. 0,2 cm larg., cilíndrico, amarelado a castanho. Frondes alternas distantes 6-9 mm. Lâmina bipinada; raque 1-2 mm larg., castanha, tricomas amarelados; pinas opostas; pínulas alternas; pinas estéreis 6,9-27 × 5,2-18 $\mathrm{cm}$, tricomas ca 0,4 mm compr., basais; peciólulo 13-26 × 0,9-1 mm; pínulas estéreis 1,8-13,3 $\times$ 0,8-2,1 mm, lanceoladas a lineares, base truncada, ápice estreito-agudo, cartáceas, margem denteadoserreada, nervuras livres 2-4 bifurcadas; peciólulo 2-8 $\mathrm{mm} \times 0,6-10 \mathrm{~mm}$; pinas férteis $6,4-23,3$ $\times$ 6-23,3 cm; peciólulo 13-39 × 0,6-1,5 mm; pínulas férteis $1,8-12,2 \times 0,7-2,2 \mathrm{~cm}$, lanceoladas a lineares, base truncada raro biauriculada, ápice estreito-agudo; peciólulo 2-8 $\mathrm{mm} \times 0,5-2 \mathrm{~mm}$. Segmentos férteis 1-6×1 mm, marginais, situados da base ao meio da pínula, às vezes até o ápice.

Material examinado: Andaraí, 23.IX.2007, J.L. Ferreira et al. 101 (HUEFS). Jacobina, 14.X.2007, J.L. Ferreira \& F. França 174 (HUEFS). Utinga, 21.IX.2007, J.L. Ferreira et al. 86 (HUEFS).

Lygodium volubile é facilmente distinguida pela presença de pínulas lanceoladas a lineares com base truncada às vezes biauriculada e nervuras livres bifurcadas. Em espécimes estéreis, algumas pínulas apicais podem não estar completamente divididas, aparentando uma única pínula dicotômica, característica bastante comum que sugere a diferenciação incompleta das pínulas. $\mathrm{Na}$ área de estudo, L. volubile pode formar densas populações que crescem por vários metros de altura e tomam vasta extensão, acompanhando o leito dos rios.

É distribuída na América Tropical, desde o México, até a Argentina e o Brasil (Acre, Amazonas, Bahia, Maranhão, Minas Gerais, Pará, Paraná, Pernambuco, Rio de Janeiro, Rio Grande do Sul, Santa Catarina e São Paulo). Na Chapada Diamantina, esta espécie possui ampla distribuição, ocorrendo às margens dos rios e córregos permanentes, às vezes, as margens dos temporários.
3. Schizaeaceae Kaulf., Wesen Farrenkr. 119. 1827.

Schizaeaceae inclui os gêneros Actinostachys Wall. e Schizaea Sm., com aproximadamente 30 espécies pantropicais, com poucas espécies extratropicais: sul da Índia e norte da Austrália (Smith et al. 2006). Na América, é encontrada desde o sul da Flórida, até o Brasil (Tryon \& Tryon 1982), onde ocorrem duas espécies de Actinostachys e cinco de Schizaea (Barros et al. 2010c).

Schizaea Sm., Mém. Acad. Roy. Sci. Turin 5: 419, pl. 9, f. 9, 1793.

3.1. Schizaea elegans (Vahl) Sw., J. Bot. (Schrader) 1800(2): 103. 1801.

Fig. 21-n

Plantas ca. $50 \mathrm{~cm}$ alt. Rizoma $2-7 \mathrm{~mm}$ diâm., enegrecido, tricomas ca. $3 \mathrm{~mm}$, amarelados. Frondes eretas. Estípite 10,5-49,1 × 0,08-0,2 $\mathrm{cm}$, delgado, amarelado a ferrugíneo, tricomas concentrados na base. Lâmina 6,2-12 cm compr., alterna, inteira, dicotomicamente lobada, flabelada, base atenuada a decurrente, ápice redondo, margem inteira, subcoriácea a coriácea, glabrescente, nervuras livres 4-5 bifurcadas; lobos foliares 5,6-10,2 × 0,4-2,2 cm. Segmentos férteis $0,3-1,1 \times 0,3-0,6 \mathrm{~cm}$, pinatífidos, ao final das nervuras, lanoso, tricomas ca. $0,8 \mathrm{~mm}$; peciólulos dos segmentos férteis ca $3 \mathrm{~mm}$ compr.

Material examinado: Andaraí, 23.IX.2007, J.L. Ferreira et al. 104 (HUEFS). Jacobina, 2.IV.1999, R.M. Harley \& A.M. Giulietti 53687 (ALCB, IPA, HRB, HUEFS). Miguel Calmon, 8.V.2005, J.G. Freitas et al. 36 (HUEFS).

Esta espécie ocorre na América Tropical, desde o sul da Flórida, México, América Central, Antilhas, do norte da América do Sul ao sul do Brasil (Acre, Amazonas, Bahia, Espírito Santo, Minas Gerais, Pará, Paraná, Pernambuco, Rio de Janeiro, Rondônia, Roraima, Santa Catarina e São Paulo). Na Chapada Diamantina, esta espécie encontra-se bem distribuída, preferindo as matas mais densas, sombreadas e úmidas e onde há pouca ação antrópica.

\section{Agradecimentos}

Dr. John T. Mickel (NYBG) pelo auxílio nas identificações e ao Programa de Pós-graduação em Botânica da UEFS e ao PPBio pelo auxílio financeiro; aos herbários pela disponibilidade do acervo; ao Laboratório de Taxonomia Vegetal da UEFS pelo auxílio nos materiais de coletas; à bióloga Carla Teixeira de Lima pelas ilustrações. 


\section{Referências}

Bandeira, R.L.S. 1995. Chapada Diamantina: história, riquezas e encantos. Onavlis, Salvador. 244p.

Barros, I.C.L.; Santiago, A.C.P. \& Pereira, A.F.N. 2010a. Anemiaceae. In: Forzza, R.C. et al. (eds.). Lista de Espécies da Flora do Brasil. Jardim Botânico do Rio de Janeiro. Disponível em <http://floradobrasil.jbrj. gov.br/2010/FB090588>. Acesso em 8 Ago 2011.

Barros, I.C.L.; Santiago, A.C.P. \& Pereira, A.F.N. 2010b. Lygodiaceae. In: Forzza, R.C. et al. (eds.). Lista de Espécies da Flora do Brasil. Jardim Botânico do Rio de Janeiro. Disponível em <http:// floradobrasil.jbrj.gov.br/2010/FB091479>. Acesso em 8 Ago 2011.

Barros, I.C.L.; Santiago, A.C.P. \& Pereira, A.F.N. 2010c. Schizaeaceae. In: Forzza, R.C. et al .(eds.). Lista de Espécies da Flora do Brasil. Jardim Botânico do Rio de Janeiro. Disponível em $<$ http://floradobrasil.jbrj. gov.br/2010/FB092037>. Acesso em 8 Ago 2011.

Franca-Rocha, W.J.S.; Chaves, J.M.; Rocha, C.C.; Funch, L. \& Juncá, F.A. 2005. Avaliação ecológica rápida da Chapada Diamantina. In: Juncá, F.A.; Funch, L. \& Rocha, W. (eds.). Biodiversidade e Conservação da Chapada Diamantina. Ministério do Meio Ambiente, Brasília. Pp. 29-45.

Kramer, K.U. 1990. Schizaeaceae. In: Kubtzki, K. (ed.). The families and genera of vascular plants. Vol. 1. Kramer, K.S. \& Green, P.S. (eds.). Pteridophytes and Gymnosperms. Springer-Verlag, Berlin. Pp. 258-263.

Lellinger, D.B. 2002. A modern multilingual glossary for Taxonomic Pteridology. American Fern Society, Washington. 263p.
Mickel, J.T. 1982. The genus Anemia (Schizaeaceae) in Mexico. Brittonia 34: 388-413.

Mickel, J.T. \& Smith, A. 2004. The Pteridophytes of Mexico. Memoirs of the New York Botanical Garden 88: 1-1055.

Moran, R. 1995. Schizaeaceae. In: Davise, G.; Sousa, M. \& Knapp, S. Flora Mesoamericana. Vol. 1. In: Moran, R. \& Riba, R. (eds.). Psilotaceae a Salviniaceae. Universidad Nacional Autónoma de México, México. 52p.

Pichi-Sermolli, R.E.G. 1996. Authors of the scientific names in Pteridophyta. Royal Botanic Gardens, Kew. 78p.

Reed, C.F. 1947. The phylogeny and ontogeny of the Pteropsida, I-Schizaeales. Boletim da Sociedade Broteriana 2: 71-197.

Smith, A.R.; Pryer, K.M.; Schuettpelz, E.; Korall, P.; Schneider, H. \& Wolf, P.G. 2006. A classification for extant ferns. Taxon 55: 705-731.

Thiers, B. 2010 [continuously updated]. Index Herbariorum: a global directory of public herbaria and associated staff. New York Botanical Garden's Virtual Herbarium. Disponível em $<\mathrm{http}$ :// sweetgum.nybg.org/ih>. Acesso em 8 Ago 2011.

Tryon, R.M. 1972. Endemic areas and geographic speciation in Tropical American ferns. Biotropica 4: 121-131.

Tryon, R.M. \& Tryon, A. 1982. Ferns and allied plants, with special reference to Tropical America, Springer-Verlag, New York. 897p.

Windisch, P.G. 1992. Pteridófitas da região norteocidental do Estado de São Paulo. 2a. ed. UNESP, São José do Rio Preto. 110p. 